\title{
Towards understanding potential atmospheric contributions to abrupt climate changes: characterizing changes to the North Atlantic eddy-driven jet over the last deglaciation
}

Heather J. Andres and Lev Tarasov

Correspondence to: Heather J. Andres (handres@mun.ca)

The copyright of individual parts of the supplement might differ from the CC BY 4.0 License. 


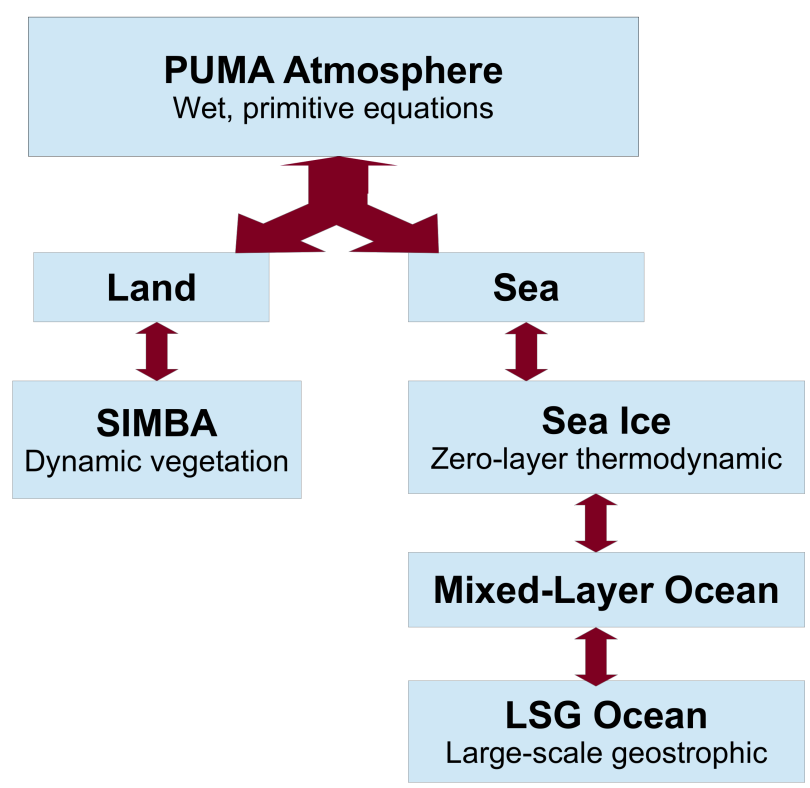

Figure S1. Conceptual schematic of how different model sub-components interact in PlaSim version 16.

\section{S1 Detailed Description of PlaSim}

PlaSim's atmosphere component, PUMA, controls the execution of this model by exchanging surface data with both the land surface and sea components and facilitating the exchange of fields between them. The sea component attenuates incoming radiation through any sea ice thickness and passes the resulting heat fluxes and wind stresses to a mixed-layer ocean model

5 of thickness $50 \mathrm{~m}$. The mixed-layer ocean model adjusts mixed-layer temperatures (Tmix) in response to incoming heat fluxes and returns Tmix to the sea ice component as a lower boundary. Where the ocean is covered with sea ice or where Tmix is lower than the freezing temperature, Tmix is changed to the freezing/melting temperature and the consequent heat fluxes are used to increase or reduce sea ice thickness as appropriate. Note that the sea ice model only evaluates thermodynamic changes and does not advect the ice with ocean currents or wind forcing.

10 The land component determines land surface temperatures in 5 soil layers, based on local energy balance (Lunkeit et al., 2012). Hydrology and runoff are evaluated through the use of a single reservoir or bucket-depth. This bucket depth depends on the vegetation type in the grid cell. Excess water is lost from the cell via runoff and is advected to ocean grid cells following topographic slopes calculated on the model grid. Runoff amounts are returned to the atmosphere, which passes the information through the sea ice and mixed-layer components to the LSG ocean model. Additionally, PlaSim includes a dynamic vegetation model, SIMBA, which estimates vegetative changes from surface atmospheric conditions, precipitation and evaporation, incoming short-wave radiation and carbon dioxide concentrations (Lunkeit et al., 2012). These vegetative changes, in turn, affect the atmosphere through changes to the surface albedo, roughness, temperature and humidity. No vegetation calculation is performed in glaciated regions, which are prescribed.

Note that due to the mixed-layer ocean and LSG being on different grids, ocean variables are interpolated when passed 20 between these two components. Heat fluxes are thus adjusted by adding a correction factor to all ocean grid cells that offsets differences in the area-weighted global average values from both grids. This allows for the land-sea masks to differ between the slab-ocean model and LSG without creating a substantial model drift. 


\section{S1.0.1 Model Modifications}

Boundary condition changes were implemented as follows. At the start of every simulation year, the topography, land-sea mask, ice mask and surface roughness datasets are read in or interpolated from source data. The number of sea grid points are calculated and the soil temperature of the top layer is initialized to the surface air temperature at the previous time step.

5 This allows cells that transition from ocean to land to have defined surface temperatures. From these data, runoff patterns and velocities, albedo, and other surface parameters are calculated. Where land grid cells become ocean, sea surface temperatures and sea ice are initialized to interpolations from the nearest LSG grid cells. Then, the model performs its integration.

Additional changes included modifying LSG to run with PlaSim at T42 and activating the diurnal cycle. These two changes necessitated retuning the model. PlaSim was tuned to preindustrial conditions by modifying four different radiation parameters, all of which are bounded by values of zero and one. A set of 30 initial random selections for these parameters were constructed, and preindustrial atmosphere general circulation model simulations (year 1850) of 10-years' duration were performed using each set. Sea ice and sea-surface temperatures were prescribed to adhere to AMIP II values averaged over years 1870 to 1899 (Taylor et al., 2000). Global-average, net top-of-atmosphere (TOA) fluxes were calculated, as well as surface sensible and latent heat and shortwave and longwave fluxes. These radiation fields were compared against fluxes from CMIP5 models presented in Table 2 of Wild et al. (2015). Those values correspond to present day fluxes, so they were adjusted to estimate preindustrial values by shifting them according to flux differences between both time periods extracted from PlaSim AGCM simulations. For every run, each flux value was compared to the corresponding reference value, and if it lay within $\pm 2 \mathrm{~W} / \mathrm{m}^{2}$ (or $\pm 1 \mathrm{~W} / \mathrm{m}^{2}$ for TOA net flux and $\pm 3 \mathrm{~W} / \mathrm{m}^{2}$ for surface latent heat), then that metric value was deemed within tolerance. Those parameter sets that yielded the largest unique set of flux terms within the specified thresholds were identified as Pareto-optimal (Fonseca and Fleming, 1995) and retained. Then, a new set of random parameters were selected in the vicinity of each of these optimal sets to refine the selections. As a result, four different tuning configurations were identified, and they form the basis of the four-member ensemble of transient simulations performed here.

\section{S2 Split jet occurrences}

Both the PlaSim simulations and TraCE-21ka exhibit months when the location of the jet is identified to be situated further north than the southern margin of the NAIS. In Figures S3, S4 and 11, these instances are clearly separated from the rest of the distribution, although the timing of their first occurring differs between ensemble members. The number of instances are fewer in the TraCE-21ka experiment and are less separated from the rest of the distribution in Figure 12. In the jet latitudes diagnosed over $90^{\circ} \mathrm{W}$ to $0^{\circ} \mathrm{W}$, these anomalous cases first arise between years $15 \mathrm{ka}$ BP and $14 \mathrm{ka}$ BP. In contrast, the instances of negative jet tilt and anomalous northern jet positions on the western side of the jet first arise between 14ka BP and $13 \mathrm{ka} \mathrm{BP}$. The first anomalous cases arise out of limitations to the algorithm used to identify the NAtl eddy-driven jet latitude. The later cases reflect temporary changes in the structure of winds over eastern NAmer. Three types of anomalous winds make up these instances altogether, which are described below.

The first type of anomalous jet is the only one that occurs from $15 \mathrm{ka} \mathrm{BP}$ to $14 \mathrm{ka} \mathrm{BP}$, and it is only detected when the jet is diagnosed over its entire range, but not when diagnosed only over the west. Identifying a northern position for the jet of this type represents an error in the detection algorithm due to the latitudinal position of the winds over the eastern NAtl aligning with the latitude of winds along the northern slope of the NAIS. Zonally averaging thereby yields a maximum at that latitude, although the bulk of the winds are routed south of the ice sheet. In Figure S6, zonal wind anomalies over eastern NAmer are weak. Instead, this type exhibits anomalously northern-situated winds over the eastern NAtl compared to other months during the same century of simulation. This explains why this type of jet anomaly does not exhibit a corresponding signal in the jet tilt or the jet detected only over eastern NAmer.

The second type of anomalous jet occurs when the winds along the northern face of the NAIS become stronger than those along the southern margin of the ice sheet. This is the result of a northward shift in the zonal winds around the entire hemisphere, although its effects are strongest over eastern NAmer and the NAtl. The northern position of the jet for this type is detected when averaged over the entire range and over eastern NAmer. It does not correspond with negative tilts, however. 

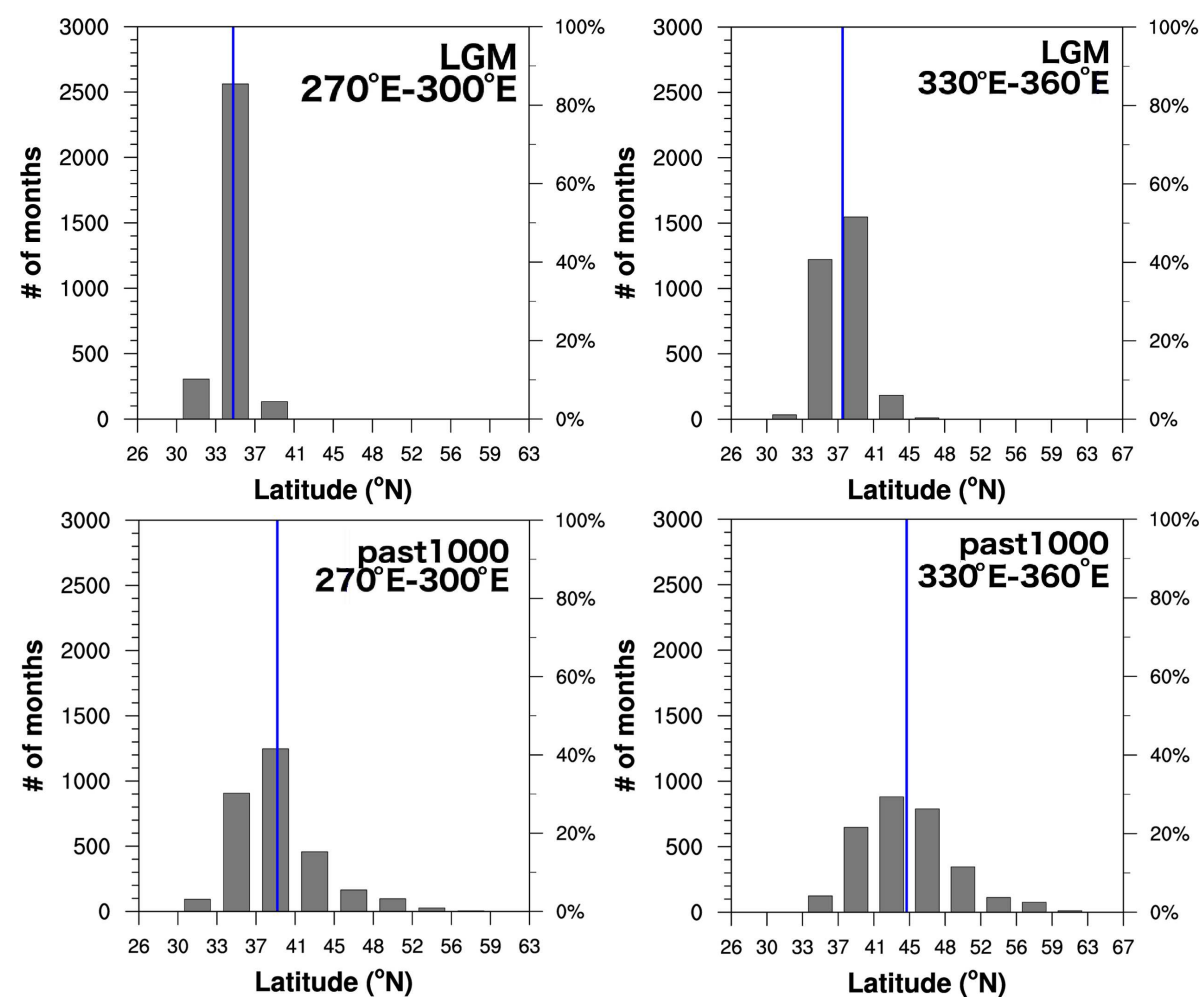

Figure S2. Histograms of latitudes corresponding to peak NAtl zonal winds for the TraCE-21ka experiment over the western and eastern regions of the jet during indicated periods. Vertical blue lines indicate mean jet latitudes for the time period.

The third type of anomalous jet is similar to the second type, except that the northward shifting of the jet is isolated to NAmer. In contrast, the winds over the eastern NAtl have their peak values further south than climatology. This case leads to the most pronounced negative values of jet tilt.

As the NAIS retreats, the northern branch of winds merges with the predominant winds passing south of the ice sheet, and 5 the cases of northward-positioned jets become indistinguishable from the rest of the distribution. 

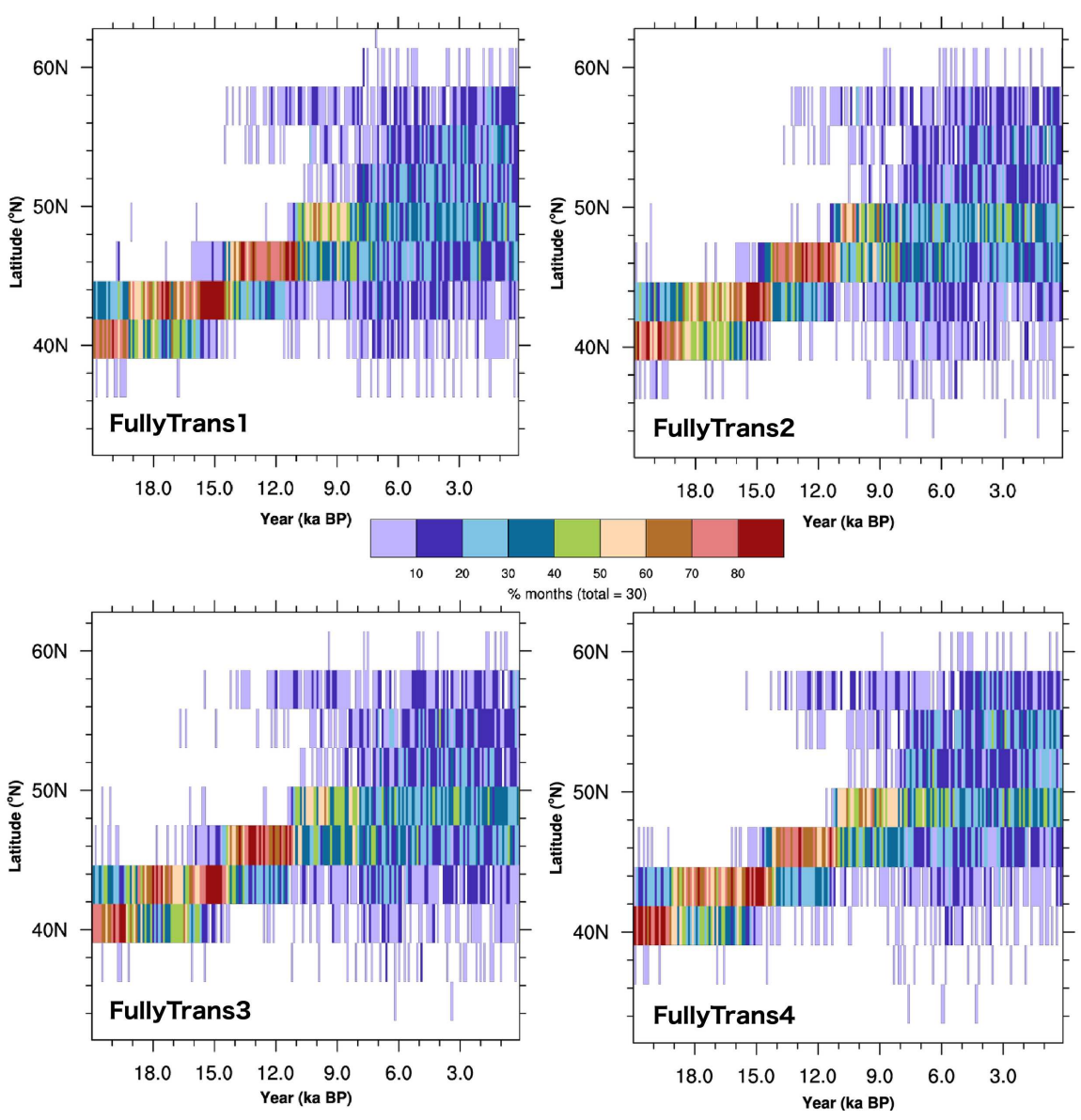

Figure S3. Frequency maps of zonal mean of NAtl lower-level jet latitudes in 10 successive winter seasons for all fully transient ensemble members. Colours indicate the number of months with peak zonal winds within each latitude bin, which correspond to latitude ranges in PlaSim at T42.

\section{References}

Fonseca, C. M. and Fleming, P. J.: An overview of evolutionary algorithms in multiobjective optimization, Evolutionary Computation, 3, 1-16, 1995.

Lofverstrom, M. and Lora, J. M.: Abrupt regime shifts in the North Atlantic atmospheric circulation over the last deglaciation, Geophysical

Research Letters, 44, 8047-8055, https://doi.org/10.1002/2017GL074274, 2017.

Lunkeit, F., Borth, H., Bottinger, M., Fraedrich, K., Jansen, H., Kirk, E., Kleidon, A., Luksch, U., Paiewonsky, P., Schubert, S., Sielmann, S., and Wan, H.: Planet Simulator reference manual version 16, Tech. rep., University of Hamburg, Hamburg, DE, last Updated: February 6, 2012, 2012.

Taylor, K. E., Williamson, D., and Zwiers, F.: The sea surface temperature and sea-ice concentration boundary conditions for AMIP II simulations, Tech. rep., Program for Climate Model Diagnosis and Intercomparison, Lawrence Livermore National Laboratory, Livermore, CA, USA, 2000.

Wild, M., Folini, D., Hakuba, M. Z., Schar, C., Seneviratne, S. I., Kato, S., Rutan, D., Ammann, C., Wood, E. F., and Konig-Langlo, G.: The energy balance over land and oceans: an assessment based on direct observations and CMIP5 climate models, Climate Dynamics, 44, 3393-3429, https://doi.org/10.1007/s00382-014-2430-z, 2015. 

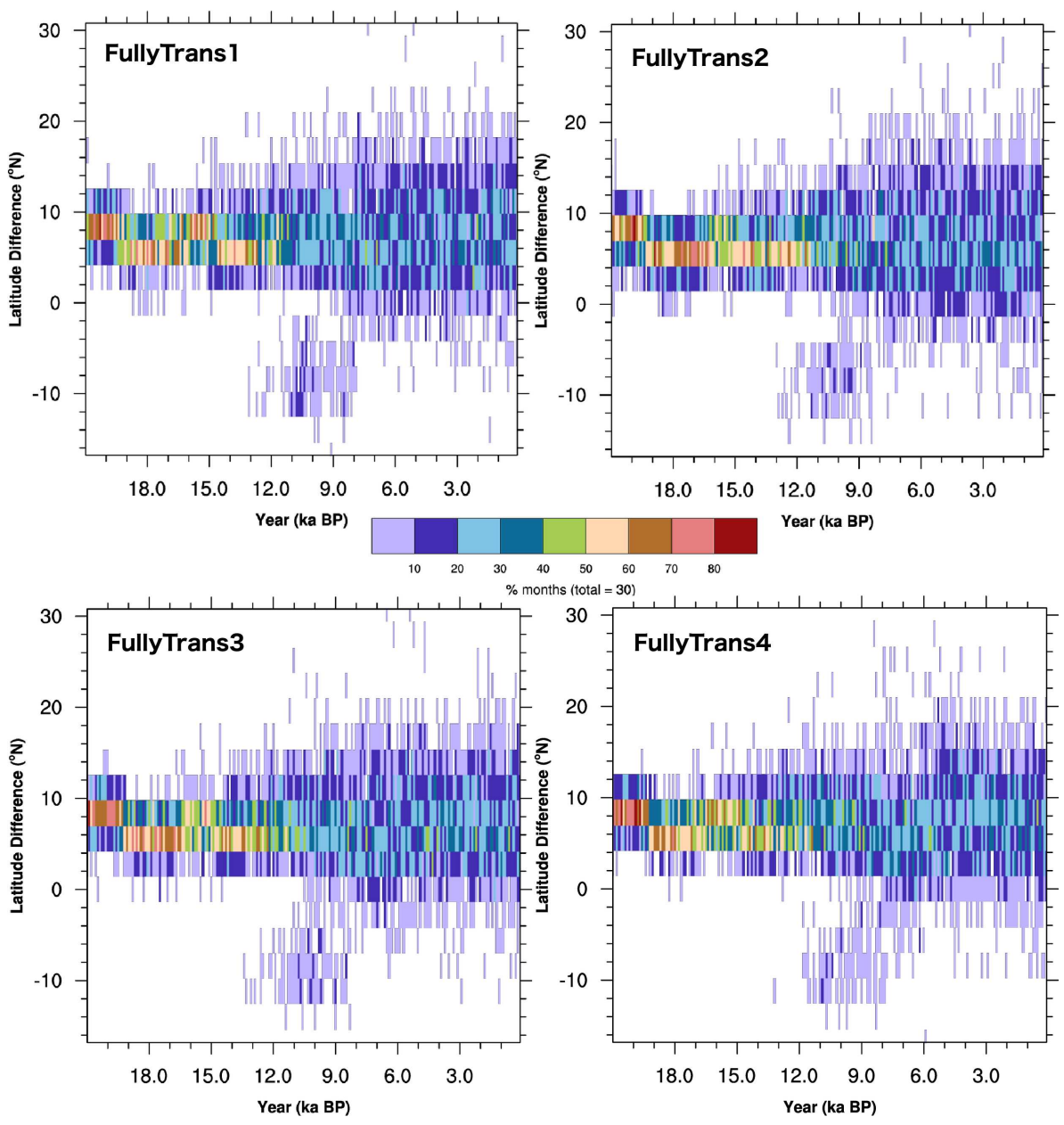

Figure S4. Frequency maps of NAtl lower-level jet tilt in 10 successive winter seasons for FullyTrans1, FullyTrans2, FullyTrans3, and FullyTrans4. Colours indicate the number of months with the difference in jet latitudes between $330^{\circ} \mathrm{E}$ to $360^{\circ} \mathrm{E}$ and $270^{\circ} \mathrm{E}$ to $300^{\circ} \mathrm{E}$ within each bin of width $2.8^{\circ}$.

Table S1. Coupled Model Intercomparison Project 5 simulations included in the the multi-model ensemble plots presented in this study.

\begin{tabular}{|c|c|c|c|c|c|}
\hline Institute ID & Model Name & \multicolumn{2}{|c|}{ past1000 } & \multicolumn{2}{c|}{ lgm } \\
& & label & years & label & years \\
\hline NCAR & CCSM4 & r1i1p1 & $085001-185012$ & r1i1p1 & $180001-190012$ \\
\hline NASA GISS & GISS-E2-R & r1i1p123 & $0850-1850$ & r1i1p150 & $3000-3099$ \\
\hline NASA GISS & GISS-E2-R & r1i1p126 & $0850-1850$ & rli1p151 & $3000-3099$ \\
\hline MIROC & MIROC-ESM & r1i1p1 & $085001-184912$ & r1i1p1 & $460001-469912$ \\
\hline MPI-M & MPI-ESM-P & r1i1p1 & $085001-184912$ & r1i1p1 & $185001-194912$ \\
\hline MPI-M & MPI-ESM-P & & & r1i1p2 & $185001-194912$ \\
\hline MRI & MRI-CGCM3 & r1i1p1 & $0850-1850$ & r1i1p1 & $250101-260012$ \\
\hline
\end{tabular}



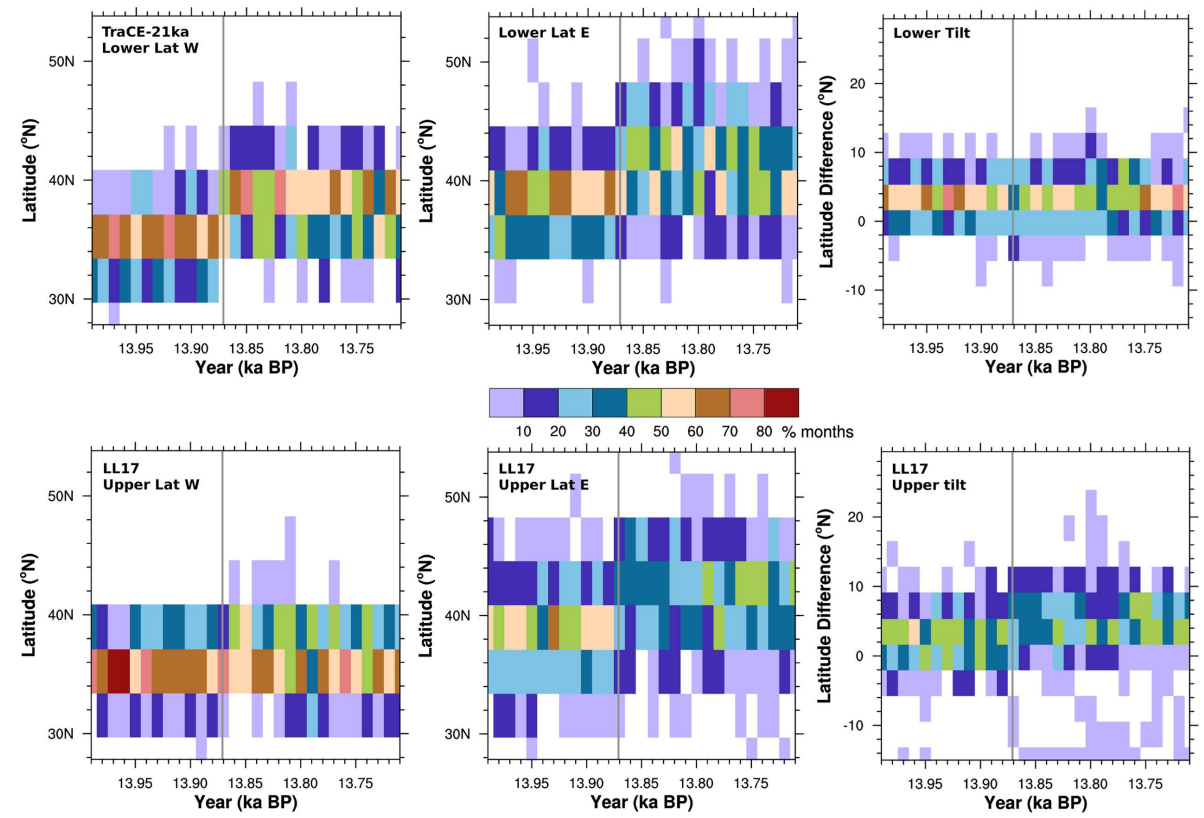

Figure S5. Frequency maps for jet tilt in the western and eastern regions, and jet tilt around the time of the main transition (13.871ka BP) in the TraCE-21ka experiment. The top row are calculated similarly to the rest of this study, over levels $700 \mathrm{hPa}$ to $925 \mathrm{hPa}$, with western and eastern regions defined as $270^{\circ} \mathrm{E}$ to $300^{\circ} \mathrm{E}$ and $330^{\circ} \mathrm{E}$ to $360^{\circ} \mathrm{E}$, respectively. Statistics in the bottom row are calculated following Lofverstrom and Lora (2017), at $250 \mathrm{hPa}$ with western and eastern regions defined as $280^{\circ} \mathrm{E}$ to $290^{\circ} \mathrm{E}$ and $340^{\circ} \mathrm{E}$ to $350^{\circ} \mathrm{E}$, respectively. The vertical grey lines mark year $13.871 \mathrm{ka} \mathrm{BP}$. 

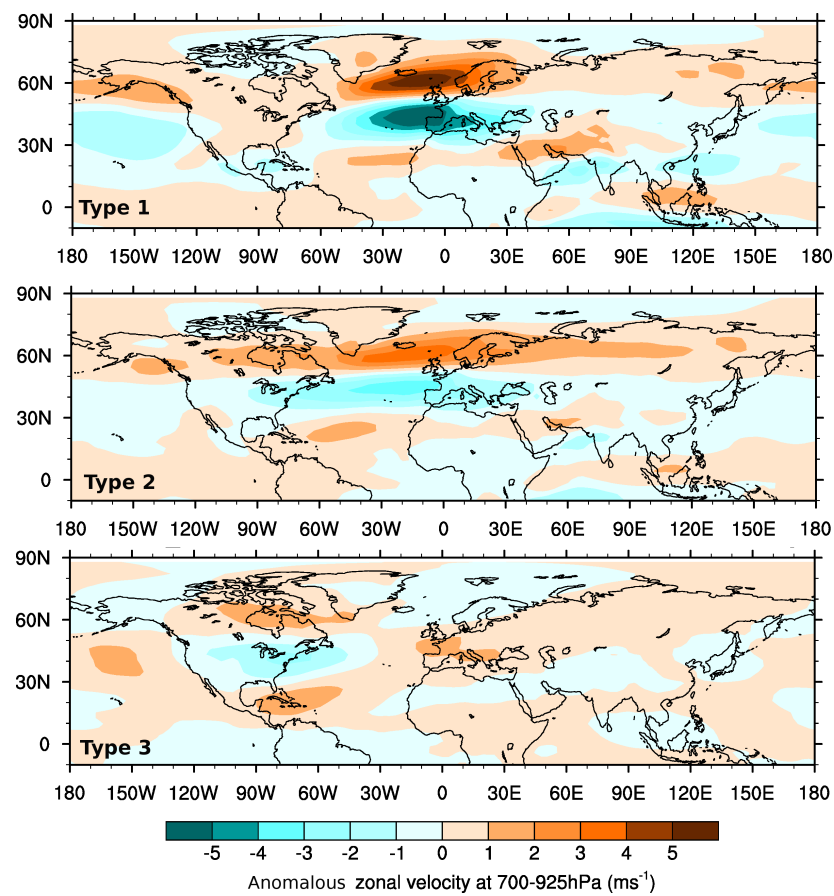

Figure S6. Composite plots of zonal wind anomalies over levels $700 \mathrm{hPa}$ to $925 \mathrm{hPa}$ during months when the NAtl eddy-driven jet is detected at a more northern position and separate from the rest of the distribution. The months are organized according to their type, which are described in the text. 

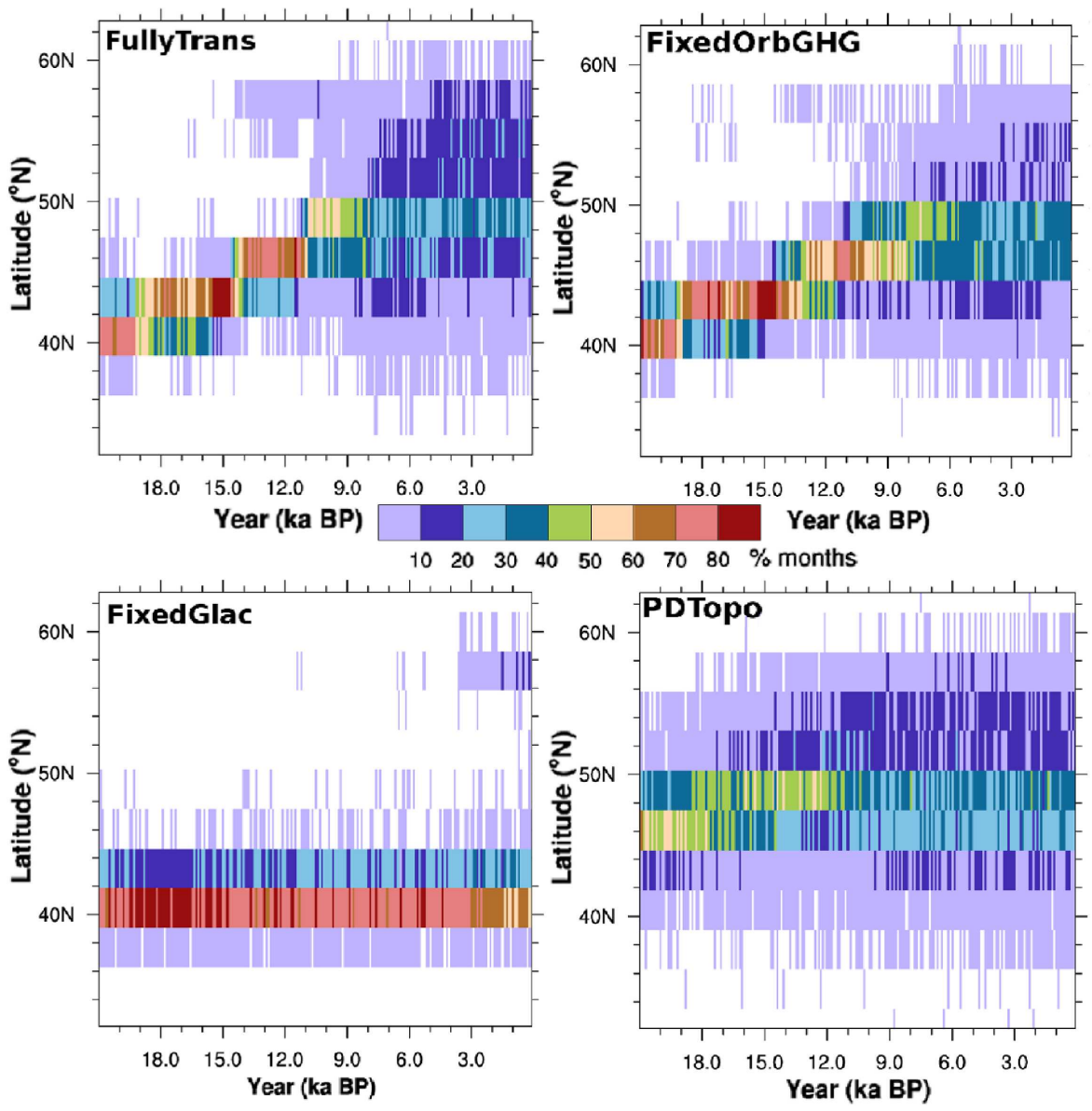

Figure S7. Frequency maps of NAtl lower-level jet latitudes calculated from $270^{\circ} \mathrm{E}$ to $360^{\circ} \mathrm{E}$ in 10 successive winter seasons accumulated over all ensemble members of the FullyTrans, FixedOrbGHG, FixedGlac and PDTopo experiments. Colours indicate the percentage of months with peak zonal winds within each latitude bin of width $2.8^{\circ}$ at T42. 

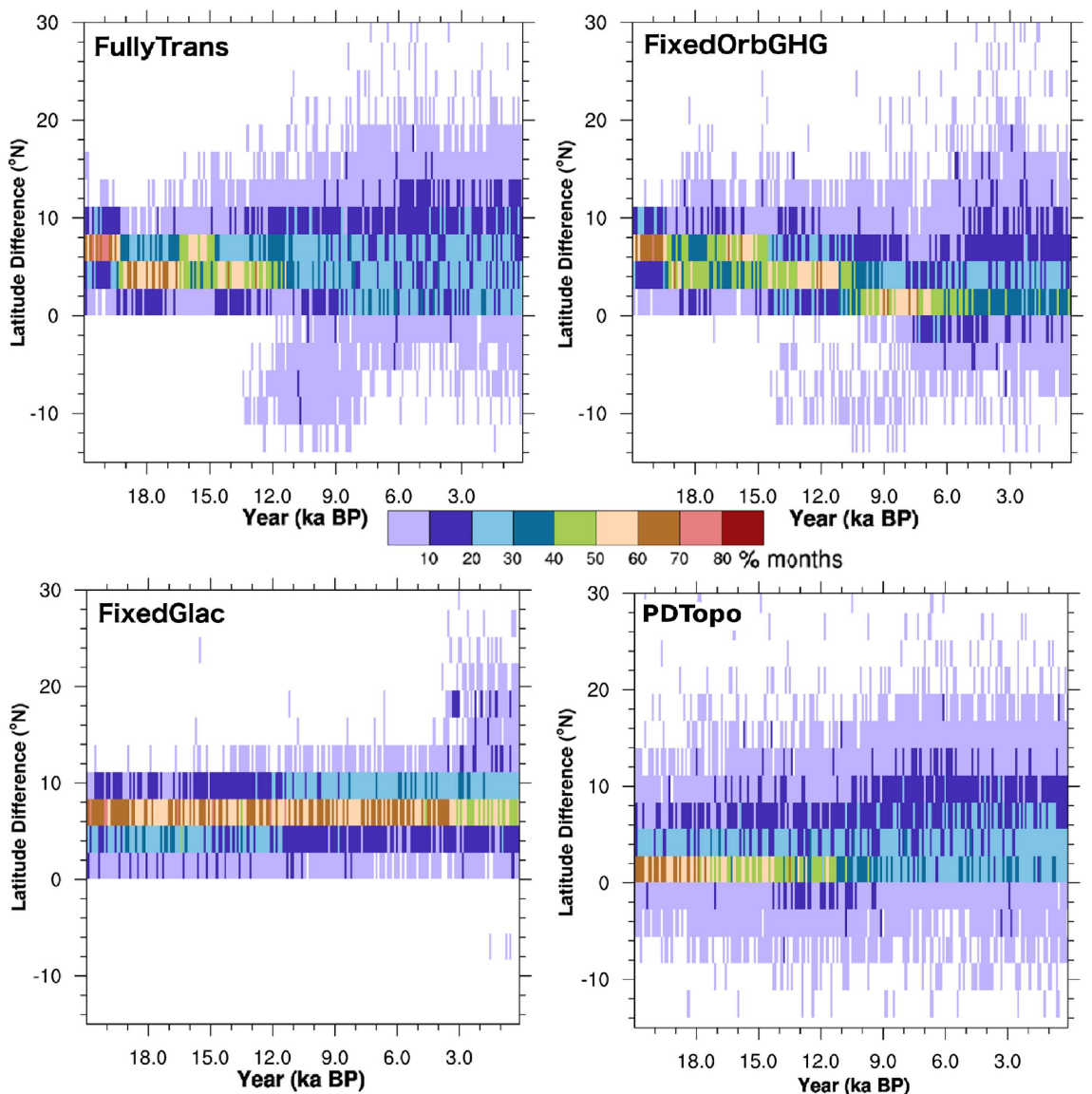

Figure S8. Frequency maps of NAtl lower-level jet tilt in 10 successive winter seasons accumulated over all ensemble members of the FullyTrans, FixedOrbGHG, FixedGlac and PDTopo experiments. Colours indicate the percentage of months with peak zonal winds within each latitude bin of width $2.8^{\circ}$ at $\mathrm{T} 42$. 

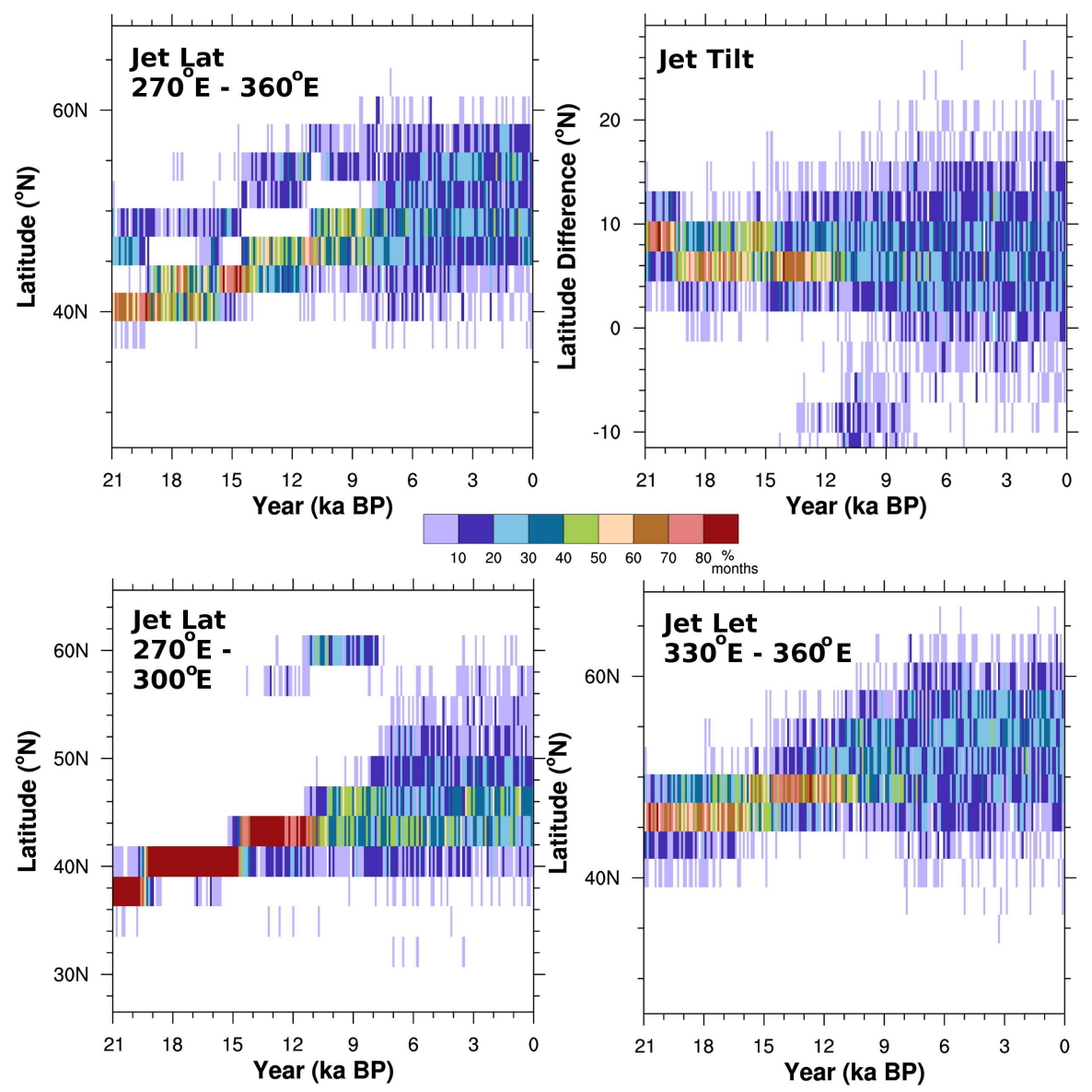

Figure S9. Frequency maps of NAtl lower-level jet latitude (averaged over three different regions) and tilt in 10 successive winter seasons from the FullyTrans1 simulation. Winds are extracted at $850 \mathrm{hPa}$, and grid cells where the surface lies above this pressure level are not included in the analysis. Colours indicate the percentage of months with peak zonal winds within each latitude bin of width $2.8^{\circ}$ at $\mathrm{T} 42$. 